Article

\title{
Hormonal Receptor Status Determines Prognostic Significance of FGFR2 in Invasive Breast Carcinoma
}

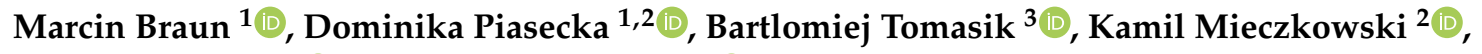 \\ Konrad Stawiski ${ }^{3}{ }^{\circledR}$, Aleksandra Zielinska ${ }^{1}$, Janusz Kopczynski ${ }^{4}$, Dariusz Nejc ${ }^{5}$, \\ Radzislaw Kordek ${ }^{1}$, Rafal Sadej ${ }^{2, *(D)}$ and Hanna M. Romanska ${ }^{1, *}$ \\ 1 Department of Pathology, Chair of Oncology, Medical University of Lodz, 92-213 Lodz, Poland; \\ marcin.braun@umed.lodz.pl (M.B.); dominika.piasecka@gumed.edu.pl (D.P.); \\ aleksandra.zielinska3@stud.umed.lodz.pl (A.Z.); radzislaw.kordek@umed.lodz.pl (R.K.) \\ 2 Department of Molecular Enzymology and Oncology, Intercollegiate Faculty of Biotechnology, \\ University of Gdansk and Medical University of Gdansk, 80-211 Gdansk, Poland; \\ kamil.mieczkowski@gumed.edu.pl \\ 3 Department of Biostatistics and Translational Medicine, Medical University of Lodz, 92-215 Lodz, Poland; \\ bartlomiej.tomasik@umed.lodz.pl (B.T.); konrad.stawiski@umed.lodz.pl (K.S.) \\ 4 Department of Surgical Pathology, Holycross Cancer Centre, 25-734 Kielce, Poland; januszko@onkol.kielce.pl \\ 5 Department of Surgical Oncology, Medical University of Lodz, 93-513 Lodz, Poland; \\ dariusz.nejc@umed.lodz.pl \\ * Correspondence: rafal.sadej@gumed.edu.pl (R.S.); hanna.romanska-knight@umed.lodz.pl (H.M.R.); \\ Tel.: +48-58-349-1469 (R.S.); +48-42-272-5605 (H.M.R.)
}

Received: 21 August 2020; Accepted: 18 September 2020; Published: 22 September 2020

check for updates

Simple Summary: FGFR2-ER-PR crosstalk leads to hormone-independent progression of breast cancer. In vitro, FGFR2 stimulates PR transcriptional activity and mediates resistance to anti-ER therapies. The postulated poor prognostic effect of FGFR2 overexpression has not been confirmed at clinical level. Our clinical data show that, counterintuitively, low expression of FGFR is linked to poor prognosis in breast cancer and its prognostic value is dependent on the hormonal receptor status, but not PR transcriptional activity. This shows, that the role of FGFR in breast cancer is more complex, which may explain unsatisfactory results of the clinical trials with FGFR inhibitors.

\begin{abstract}
Interaction between fibroblast growth factor receptor 2 (FGFR2) and estrogen/progesterone receptors (ER/PR) affects resistance to anti-ER therapies, however the prognostic value of FGFR2 in breast cancer (BCa) remains largely unexplored. We have recently showed in vitro that FGFR2-mediated signaling alters PR activity and response to anti-ER treatment. Herein, prognostic significance of FGFR2 in BCa was evaluated in relation to both ER/PR protein status and a molecular signature designed to reflect PR transcriptional activity. FGFR2 was examined in 353 BCa cases using immunohistochemistry and Nanostring-based RNA quantification. FGFR2 expression was higher in ER+PR+ and ER+PR- compared to ER-PR- cases $(p<0.001)$. Low FGFR2 was associated with higher grade $(p<0.001)$, higher Ki67 proliferation index $(p<0.001)$, and worse overall and disease-free survival ( $\mathrm{HR}=2.34$ (95\% CI: 1.26-4.34), $p=0.007$ and HR = 2.22 (95\% CI: 1.25-3.93), $p=0.006$, respectively). The poor prognostic value of low FGFR2 was apparent in ER+PR+, but not in $\mathrm{ER}+\mathrm{PR}-$ patients, and it did not depend on the expression level of PR-dependent genes. Despite the functional link between FGFR2 and ER/PR revealed by preclinical studies, the data showed a link between FGFR2 expression and poor prognosis in BCa patients.
\end{abstract}

Keywords: breast cancer; FGFR2; ER; PR; PR transcriptional profile; survival 


\section{Introduction}

The essential involvement of tumor microenvironment (TME) in breast cancer (BCa) progression and resistance to endocrine therapies has solid mechanistic and clinical foundations [1-3]. The key components of TME, i.e., cancer-associated fibroblasts and tumor-infiltrating immune cells, modulate intracellular pathways of $\mathrm{BCa}$ through direct or paracrine interactions [1-3]. In particular, fibroblast growth factor receptor 2 (FGFR2) has emerged as a principal transducer of signals between TME and ER/PR pathways $[4,5]$.

We and others have shown mechanistically that FGFR2 promotes hormone-independent tumor growth and resistance to endocrine therapies [4,5]. Activation of FGFR2 in BCa cell lines abrogated stimulating effect of estrogen on ER, while decreased FGFR2 expression enhanced cell responsiveness to estrogen [6,7]. In mice, hormone-independent tumors had higher FGFR2 expression and more abundant FGF2-secreting cancer-associated fibroblasts, compared to hormone-dependent tumors [8]. FGFR2 promoted hormone-independent BCa growth also through MAPK or PI3K/AKT-mediated phosphorylation of PR (noncanonical activation of PR), resulting in increased activity of PR, followed by its rapid degradation [8-11]. Thus, mistakenly deemed as lost, hyperactive PR may drive enhanced BCa cells proliferation and survival via ligand-independent transcriptional activation of PR-targeted genes [12]. In luminal BCa cell lines, FGFR2-mediated deregulation of both ER and/or PR signaling was shown to lead to poor response to treatment with fulvestrant or tamoxifen [13-15]. This implies, that FGFR2-mediated noncanonical activation of PR might result in its undetectability on the protein level, leading to false classification of the 'PR-hyperactive' tumors as PR-negative [16,17].

In the clinical setting, the postulated poor prognostic effect, likely to result from FGFR2/ER/PR-mediated resistance to endocrine therapies, was analyzed recently in advanced BCa patients, for whom activating genetic alterations in FGFR2 gene (mostly point mutations) were linked to resistance to anti-ER therapies [18-25]. These studies, for the most part inconclusive, involved analyses of genetic alterations of different FGFs or FGFRs genes in metastatic BCa patients subjected to various intensive therapeutic regimens, including those with developed resistance to endocrine therapy. Analyses of a relationship between expression of FGFR2 protein, breast cancer hormone receptor status, and disease outcome also provided inconsistent results [26,27]. Given the documented interactions between FGFR2 and PR, evaluation of the prognostic value of FGFR2 in BCa should account not only for their protein levels, but also for the molecular signature of PR transcriptional activity and rapid turnover $[9,17,28,29]$.

In summary, available data from the clinic do not fully support the anticipated prognostic value of FGFR2 expression in $\mathrm{BCa}$, which partially may be due to the limited insight into FGFR2-mediated noncanonical activation of PR signaling. Herein, we addressed this issue by investigating tumoral tissue from BCa patients for prognostic significance of FGFR2 expression in relation to both hormonal receptor status and a molecular signature designed to reflect PR transcriptional activity in the context of routinely evaluated clinicopathological BCa features.

\section{Results}

\subsection{Low FGFR2 Expression Is Associated with Unfavorable Clinicopathological Characteristics Including Negative Hormonal Receptor Status}

All 353 tumors were qualified for FGFR2 staining, and 346 (98.0\%) were of satisfying quality for RNA analyses (Figure 1). Thirty-four (9.6\%) patients were ER-PR-, 73 (20.7\%) ER+PR-, and 246 (69.7\%) $\mathrm{ER}+\mathrm{PR}+$, and there were no $\mathrm{ER}-\mathrm{PR}+$ cases. $\mathrm{ER}-\mathrm{PR}-$ and $\mathrm{ER}+\mathrm{PR}-$ groups displayed poor prognostic features as compared to the $\mathrm{ER}+\mathrm{PR}+$ subtype, i.e., higher grade $(p<0.001)$ and Ki67 proliferation index (AKW $p=0.011$, post-hoc $p=0.062 \mathrm{ER}+\mathrm{PR}+\mathrm{vs}$. ER+PR- and $p=0.086 \mathrm{ER}+\mathrm{PR}+\mathrm{vs}$. ER-PR-), larger tumor size (AKW $p<0.001$, post-hoc $p=0.297 \mathrm{ER}+\mathrm{PR}+\mathrm{vs}$. ER+PR- and $p=0.007 \mathrm{ER}+\mathrm{PR}+\mathrm{vs}$. ER-PR-), and more frequent HER2 amplification $(p<0.001)$ (Table 1$)$. 


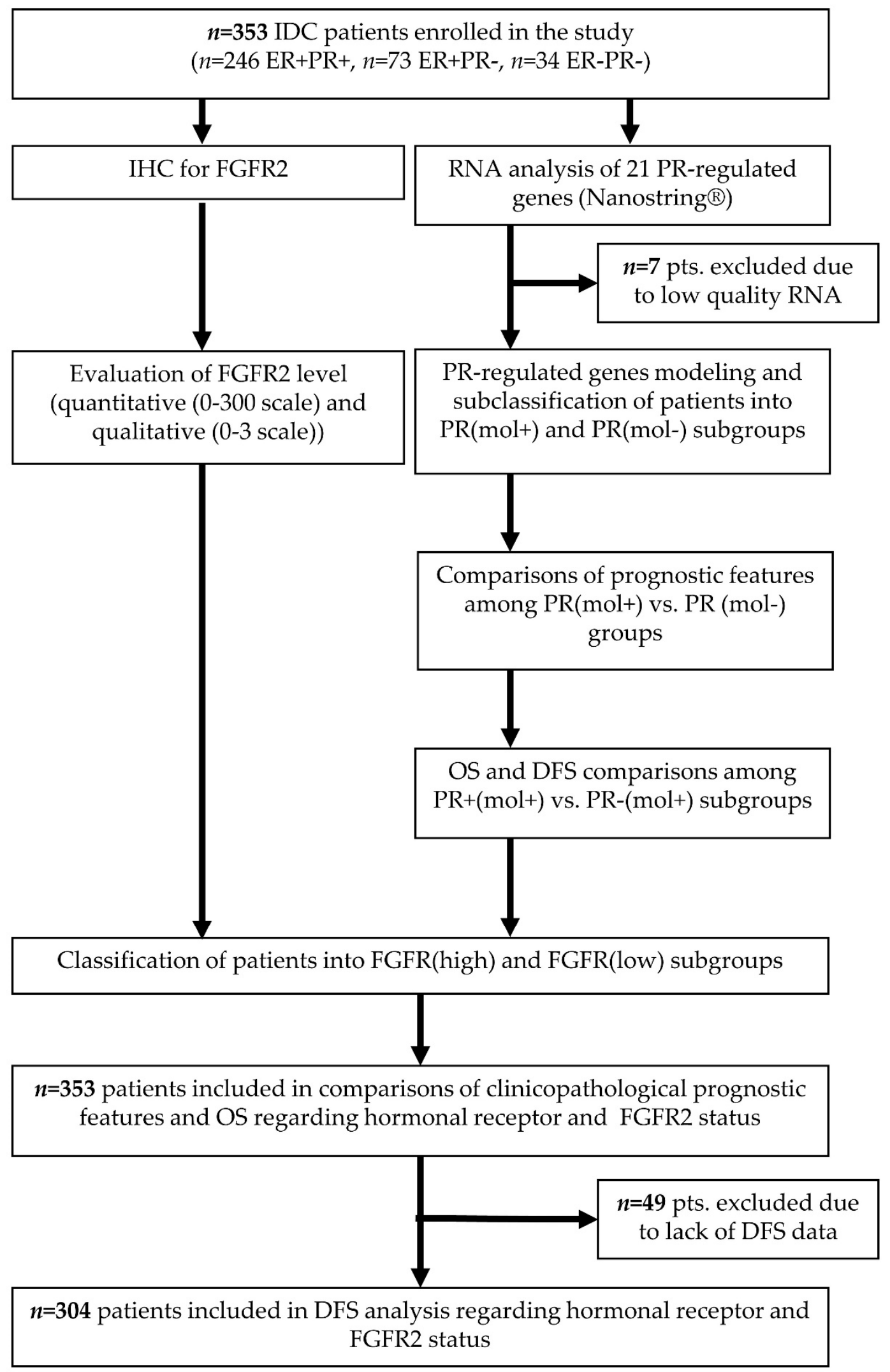

Figure 1. Flowchart of the study design with indication of numbers of patients from the original cohort included in every analysis. IDC - invasive ductal carcinoma, ER-estrogen receptor protein status, PR-progesterone receptor protein status, IHC—immunohistochemistry, FGFR2-fibroblast growth factor receptor 2 protein, $\mathrm{PR}(\mathrm{mol})$-molecular signature progesterone receptor-dependent genes, OS-overall survival, DFS—disease-free survival. 
Table 1. Pathological and clinical characteristics of the study group regarding immunohistochemistry -based hormonal receptor status. Nominal variables are presented as raw values followed by percentages of the eligible groups, and continuous variables are presented as medians and interquartile ranges in brackets.

\begin{tabular}{|c|c|c|c|c|c|}
\hline Variable & $\begin{array}{l}\text { Whole Group } \\
\begin{array}{c}n=353 \\
(100)\end{array}\end{array}$ & $\begin{array}{c}\text { ER-PR- } \\
n=34 \\
(9.6)\end{array}$ & $\begin{array}{c}\mathrm{ER}+\mathrm{PR}- \\
n=73 \\
(20.7)\end{array}$ & $\begin{array}{c}\mathrm{ER}+\mathrm{PR}+ \\
n=246 \\
(69.7)\end{array}$ & $p$-Value \\
\hline Age (years) ${ }^{1}$ & $\begin{array}{c}63.8 \\
(55.0-71.3)\end{array}$ & $\begin{array}{c}63.6 \\
(55.7-73.1)\end{array}$ & $\begin{array}{c}64.7 \\
(60.0-70.6)\end{array}$ & $\begin{array}{c}63.6 \\
(52.7-70.8)\end{array}$ & 0.132 \\
\hline $\begin{array}{c}\text { Menopausal status }{ }^{2} \\
\text { Pre } \\
\text { Post }\end{array}$ & $\begin{array}{c}37(11.4) \\
288(88.6)\end{array}$ & $\begin{array}{c}2(6.1) \\
31(93.9)\end{array}$ & $\begin{array}{c}3(4.6) \\
62(95.4)\end{array}$ & $\begin{array}{l}32(14.1) \\
195(85.9)\end{array}$ & 0.063 \\
\hline $\begin{array}{c}\text { Grade }^{2} \\
1 \\
2 \\
3 \\
\end{array}$ & $\begin{array}{l}42(11.9) \\
227(64.3) \\
84(23.8)\end{array}$ & $\begin{array}{c}2(5.9) \\
12(35.3) \\
20(58.8)\end{array}$ & $\begin{array}{c}9(12.3) \\
43(58.9) \\
21(28.8)\end{array}$ & $\begin{array}{c}31(12.6) \\
168(69.9) \\
42(17.5)\end{array}$ & $<0.001$ * \\
\hline $\mathrm{Ki} 67(\%)^{1}$ & $\begin{array}{c}18.0 \\
(5.0-30.0)\end{array}$ & $\begin{array}{c}32.0 \\
(30.5-35.5)\end{array}$ & $\begin{array}{c}20.0 \\
(10.0-40.0)\end{array}$ & $\begin{array}{c}12.0 \\
(5.0-25.0)\end{array}$ & 0.011 * \\
\hline $\begin{array}{c}\text { HER2 amplification } \\
\text { positivity }^{2}\end{array}$ & 45 (12.7) & $12(35.3)$ & $13(17.8)$ & $20.0(8.1)$ & $<0.001$ * \\
\hline Tumor size $(\mathrm{mm})^{1}$ & $\begin{array}{c}20.0 \\
(15.0-27.0)\end{array}$ & $\begin{array}{c}25.0 \\
(15.0-35.0)\end{array}$ & $\begin{array}{c}25.0 \\
(19.0-30.0)\end{array}$ & $\begin{array}{c}20.0 \\
(15.0-25.0)\end{array}$ & 0.004 * \\
\hline $\begin{array}{l}\text { T feature }{ }^{2} \\
\text { pT1 } \\
\text { pT2 } \\
\text { pT3-4 }\end{array}$ & $\begin{array}{c}143(53.0) \\
116(43.0) \\
11(4.0)\end{array}$ & $\begin{array}{c}13(40.6) \\
16(50.0) \\
3(9.4)\end{array}$ & $\begin{aligned} 15 & (38.5) \\
22 & (56.4) \\
2 & (5.1)\end{aligned}$ & $\begin{array}{c}115(57.8) \\
78(39.2) \\
6(3.0)\end{array}$ & 0.064 \\
\hline Metastases present $^{2}$ & $116(33.5)$ & $13(42.4)$ & $25(34.7)$ & $77(32.0)$ & 0.475 \\
\hline $\begin{array}{c}\mathrm{N} \text { feature }^{2} \\
\text { pN0 } \\
\text { pN1 } \\
\text { pN2-3 }\end{array}$ & $\begin{array}{l}230(66.5) \\
81(23.4) \\
34(10.1)\end{array}$ & $\begin{array}{c}17(57.6) \\
10(30.3) \\
4(12.1)\end{array}$ & $\begin{array}{c}47(65.3) \\
16(22.2) \\
9(12.5)\end{array}$ & $\begin{array}{c}164(68.0) \\
55(22.8) \\
22(9.1)\end{array}$ & 0.733 \\
\hline $\begin{array}{c}\text { Staging }^{2} \\
\text { Very early (IA) } \\
\text { Early (IB-IIIA) } \\
\text { Advanced (IIIB-IV) }\end{array}$ & $\begin{array}{c}135(39.1) \\
189(54.8) \\
21(6.1)\end{array}$ & $\begin{array}{l}11(34.4) \\
17(53.1) \\
4(12.5)\end{array}$ & $\begin{array}{c}23(31.9) \\
45(62.5) \\
4(5.6)\end{array}$ & $\begin{array}{c}101(41.9) \\
127(52.7) \\
13(5.4)\end{array}$ & 0.289 \\
\hline Multifocality $^{2}$ & $39(14.3)$ & $3(8.8)$ & $6(15.4)$ & $30(15.0)$ & 0.622 \\
\hline DCIS present $^{2}$ & $103(29.1)$ & $10(29.4)$ & $23(31.5)$ & $70(28.3)$ & 0.871 \\
\hline Hormonotherapy $^{2}$ & $220(81.2)$ & $0(0.0)$ & $46(82.1)$ & $174(86.6)$ & $<0.001$ * \\
\hline Neoadjuvant therapy ${ }^{2}$ & $231(75.5)$ & $26(89.7)$ & $30(48.4)$ & $175(81.4)$ & $<0.001$ * \\
\hline Adjuvant chemotherapy ${ }^{2}$ & $150(62.2)$ & $25(80.7)$ & $38(66.7)$ & $87(56.9)$ & $0.032 *$ \\
\hline Adjuvant radiotherapy ${ }^{2}$ & $151(64.8)$ & $11(50.0)$ & $30(61.2)$ & $110(67.9)$ & 0.111 \\
\hline Progression/relapse ${ }^{3}$ & $30(9.8)$ & $10(31.3)$ & $8(11.9)$ & $12(5.8)$ & $<0.001 *$ \\
\hline $\begin{array}{l}\text { Disease-free survival } \\
\text { (years) }\end{array}$ & $3.9(2.7-6.4)$ & $3.6(2.2-4.5)$ & $3.8(2.5-4.9)$ & $4.2(2.9-6.6)$ & \\
\hline Deaths $^{3}$ & 41 (11.6) & $10(29.4)$ & $6(8.2)$ & $25(10.1)$ & $<0.001 *$ \\
\hline Overall survival (years) & $4.2(2.9-6.5)$ & $3.6(2.6-4.5)$ & $4.0(2.7-5.5)$ & $4.7(3.0-6.7)$ & \\
\hline
\end{tabular}

FGFR2 protein levels ranged from 0 to 300, and the median level was 95.0 (IQR: 12.0-195.0). There were $152(43.1 \%)$ negative/weakly positive (Figure $2 a)$, 73 (20.7\%) moderately positive (Figure $2 b$ ), $62(17.6 \%)$ strongly positive (Figure $2 \mathrm{c})$, and $66(18.7 \%)$ very strongly positive cases (Figure $2 \mathrm{~d}$ ). FGFR2 protein levels were significantly lower in ER-PR- versus ER+PR+, and in ER-PR- versus ER+PR- patients (AKW $p<0.001$ with post-hoc $p<0.001$ for both comparisons, Figure 3, Table S1). These differences were maintained for FGFR2 gene mRNA ( $p=0.049$ with post-hoc $p=0.057$ and $p=0.432$, respectively, Figure S1, Table S1). Expression levels of neither FGFR2 protein nor mRNA showed significant differences between ER+PR- and ER+PR+ tumors (Figure 3 and Figure S1, Table S1). 


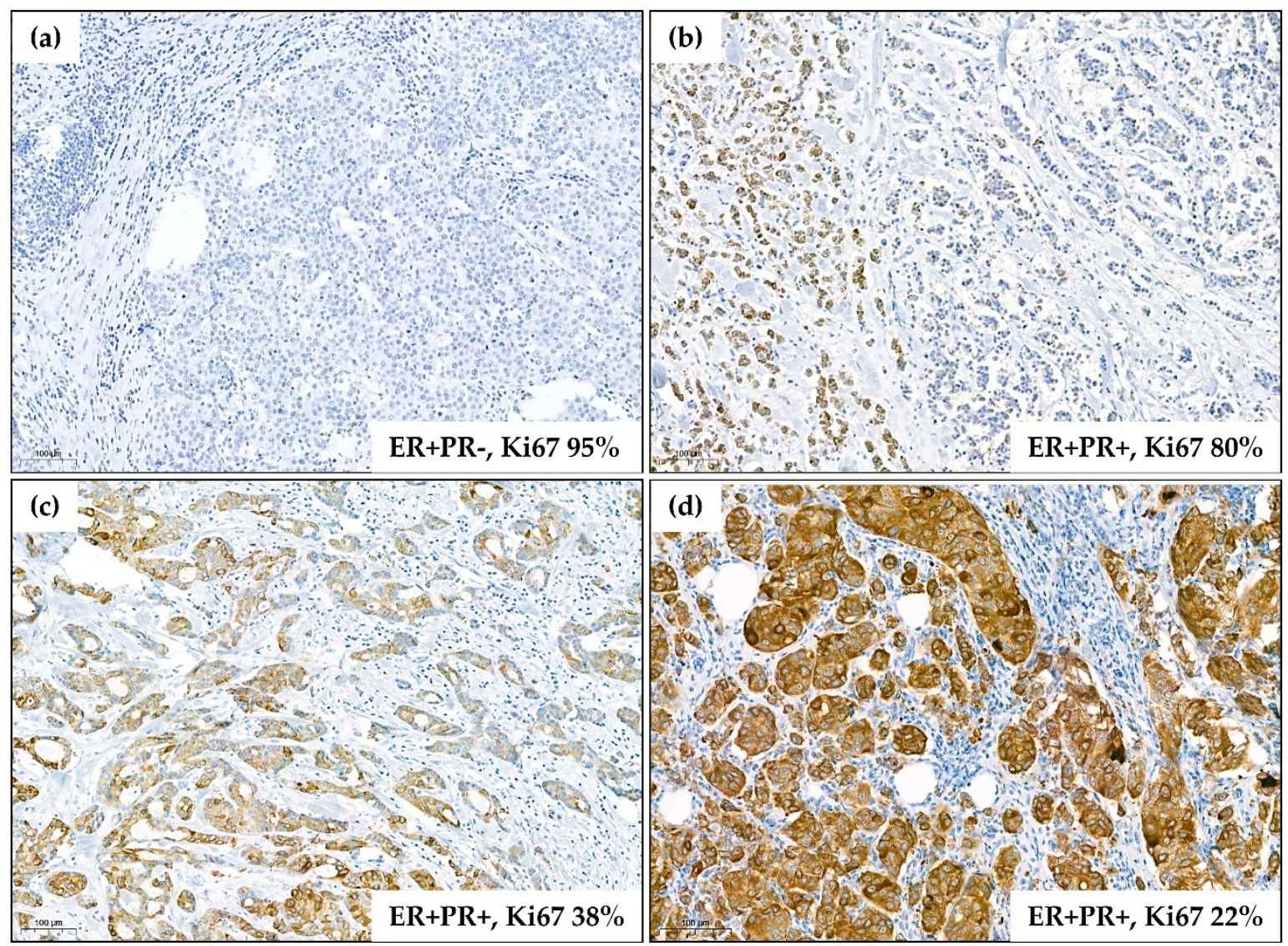

Figure 2. Representative images of immunohistostaining for FGFR2 using H00002263-M01 antibody (Abnova). Corresponding data on hormonal receptor status and Ki67 proliferation index are presented for each tumor. The images are representative for the main observations on the links between FGFR2 levels and clinicopathological features (low levels of FGFR2 associated with ER/PR negativity and high Ki67 index). (a) Negativity of cancer cells for FGFR2 (0/3 in semiquantitative scale with H-score of 0/300); (b) weak positivity for FGFR2 (1/3 in semiquantitative scale with H-score of $80(5 \times 3+30 \times$ $2+5 \times 1+60 \times 0)$ ); (c) moderate positivity for FGFR2 (2/3 in semiquantitative scale with H-score of $170(20 \times 3+35 \times 2+40 \times 1+5 \times 0))$; (d) very strong positivity for FGFR2 (3/3 in semiquantitative scale with H-score of $290(90 \times 3+10 \times 2))$. Scale bars indicating $100 \mu \mathrm{m}$ are applied on each image. 


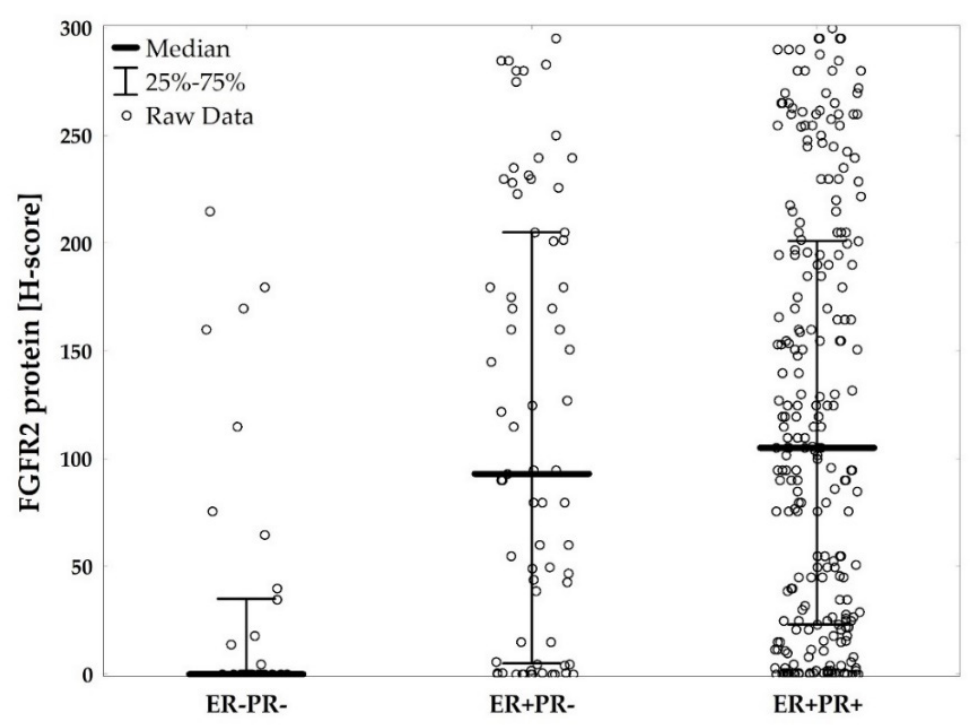

Figure 3. FGFR2 protein levels (H-score) compared between hormonal receptor status subgroups $(\mathrm{ER}-\mathrm{PR}-\mathrm{vs}$. ER+PR- vs. ER+PR+), $p<0.001$. $p$-value from Kruskal-Wallis ANOVA test.

For clinicopathological and survival analyses patients were dichotomized into FGFR2low and FGFR2high groups by 1st tercile of protein levels (H-score). FGFR2low patients were characterized by a higher both Ki67 proliferation index $(p=0.014)$ and grade $(p<0.001)$, as well as more frequent ERand PR-negativity $(p<0.001)$, than those with FGFR2high tumors (Table 2).

Table 2. Clinicopathological features in fibroblast growth factor receptor 2 (FGFR2)low versus FGFR2high patients (divided by 1st tercile of $\mathrm{H}$-score protein level). Nominal variables are presented as raw values followed by percentages of the respective groups, continuous variables are presented as medians and interquartile ranges in brackets.

\begin{tabular}{|c|c|c|c|}
\hline Variable & $\begin{array}{c}\text { FGFR2low } \\
n=117(33.1)\end{array}$ & $\begin{array}{c}\text { FGFR2high } \\
n=236(66.9)\end{array}$ & $p$-Value \\
\hline Age (years) ${ }^{1}$ & $64.6(56.5-75.2)$ & $63.4(54.2-69.9)$ & 0.078 \\
\hline $\begin{array}{c}\text { Menopausal status }^{2} \\
\text { Pre } \\
\text { Post }\end{array}$ & $\begin{array}{c}8(7.1) \\
104(92.9)\end{array}$ & $\begin{array}{c}29(13.7) \\
183(86.3)\end{array}$ & 0.078 \\
\hline $\begin{array}{c}\text { Grade }^{2} \\
1 \\
2 \\
3\end{array}$ & $\begin{array}{c}7(5.9) \\
65(55.6) \\
45(38.5)\end{array}$ & $\begin{array}{c}35(14.8) \\
162(68.6) \\
39(16.5)\end{array}$ & $<0.001$ * \\
\hline Ki67 (\%) ${ }^{1}$ & $23.5(12.0-40.0)$ & $15.0(5.0-28.0)$ & $0.014 *$ \\
\hline $\begin{array}{c}\text { HER2 amplification } \\
\text { positivity }^{2}\end{array}$ & $11(9.4)$ & $33(14.0)$ & 0.220 \\
\hline $\begin{array}{c}\text { Hormonal status }^{2} \\
\text { ER-PR- } \\
\text { ER+PR- } \\
\text { ER+PR+ }\end{array}$ & $\begin{array}{l}25(21.4) \\
22(18.8) \\
70(59.8)\end{array}$ & $\begin{array}{c}9(3.8) \\
51(21.6) \\
176(74.6)\end{array}$ & $<0.001$ * \\
\hline $\begin{array}{c}\text { PR molecular status }{ }^{2} \\
\text { PR(mol+) } \\
\text { PR(mol- })\end{array}$ & $\begin{array}{l}59(66.3) \\
30(33.7)\end{array}$ & $\begin{array}{l}145(64.4) \\
80(35.6)\end{array}$ & 0.757 \\
\hline Tumor size $(\mathrm{mm})^{1}$ & $20.0(15.0-30.0)$ & $20.0(15.0-25.0)$ & 0.898 \\
\hline
\end{tabular}


Table 2. Cont.

\begin{tabular}{|c|c|c|c|}
\hline Variable & $\begin{array}{c}\text { FGFR2low } \\
n=117(33.1)\end{array}$ & $\begin{array}{c}\text { FGFR2high } \\
n=236(66.9)\end{array}$ & $p$-Value \\
\hline $\begin{array}{c}\text { T feature } \\
\text { pT1 } \\
\text { pT2 } \\
\text { pT3-4 }\end{array}$ & $\begin{array}{c}55(51.4) \\
46(43.0 \\
6(5.6)\end{array}$ & $\begin{array}{c}88(54.0) \\
69(42.3) \\
6(3.7)\end{array}$ & 0.731 \\
\hline Metastases present ${ }^{2}$ & $44(38.6)$ & $76(32.9)$ & 0.296 \\
\hline $\begin{array}{c}\mathrm{N} \text { feature }^{2} \\
\text { pN0 } \\
\text { pN1 } \\
\text { pN2-3 }\end{array}$ & $\begin{array}{c}73(64.0) \\
30(26.3) \\
11(9.6)\end{array}$ & $\begin{array}{l}156(67.5) \\
51(22.1) \\
24(10.4)\end{array}$ & 0.682 \\
\hline $\begin{array}{c}\text { Staging }^{2} \\
\text { Very early (IA) } \\
\text { Early (IB-IIIA) } \\
\text { Advanced (IIIB-IV) }\end{array}$ & $\begin{array}{c}40(35.1) \\
69(60.5) \\
5(4.4)\end{array}$ & $\begin{array}{c}95(41.1) \\
119(51.5) \\
17(7.4)\end{array}$ & 0.234 \\
\hline DCIS present ${ }^{2}$ & $30(25.6)$ & $72(30.5)$ & 0.342 \\
\hline DFS events ${ }^{3}$ & $25(24.8)$ & $22(10.8)$ & $0.005 *$ \\
\hline $\begin{array}{c}\text { Disease-free survival } \\
\text { (years) }\end{array}$ & $3.9(2.6-6.6)$ & $3.9(2.7-5.8)$ & \\
\hline Deaths $^{3}$ & $23(19.7)$ & $18(7.6)$ & $0.003 *$ \\
\hline Overall survival (years) & $4.6(2.7-6.7)$ & $4.1(2.9-6.4)$ & \\
\hline
\end{tabular}

\subsection{Low FGFR2 Protein Is Associated with Poor Overall and Disease-Free Survival}

Median follow-up of the analyzed group was 4.2 years (IQR: 2.9-6.5) and $41(11.6 \%)$ deaths were recorded. In the univariate analyses of overall survival probability, the following clinicopathological features were associated with poor prognosis: ER-PR-, older age, large size of tumors, presence of lymph node metastases, and advanced disease (Stage IIIB-IV) (Table 1). FGFR2low patients displayed significantly worse overall survival comparing to FGFR2high patients (HR 2.34 (95\% CI: 1.26-4.34); $\log$-rank $p=0.003$, Figure $4 a$, Tables 2 and 3). The poor prognostic impact of FGFR2low status was present in $\mathrm{ER}+$ and in $\mathrm{ER}+\mathrm{PR}+$, but not in $\mathrm{ER}+\mathrm{PR}$ - patients (Figure $4 \mathrm{~b}-\mathrm{d}$ ). In the multivariate analysis, FGFR2low showed poor prognostic impact on overall survival regardless of the hormonal receptor status (HR $=2.09$ (95\% CI: 1.08-4.04)), but it was not significant when adjusted to other significant variables from the univariate analyses (only age at diagnosis maintained its significance, Table 3 and Table S2).

Table 3. Results from Cox multivariate analysis for overall survival (OS) and disease-free survival (DFS) regarding FGFR2 status adjusted for variables significant in the univariate survival analyses.

\begin{tabular}{cccc}
\hline Outcome & HR (95\% CI) Raw & $\begin{array}{c}\text { HR (95\% CI) Adjusted } \\
\text { for Hormonal Status }\end{array}$ & $\begin{array}{c}\text { HR (95\% CI) Adjusted } \\
\text { for Hormonal Status, } \\
\text { Age and Tumor Size }\end{array}$ \\
\hline $\begin{array}{c}\text { OS } \\
\text { (FGFR2high as } \\
\text { reference) } \\
\text { DFS }\end{array}$ & $\begin{array}{c}2.34(1.26-4.34), \\
p=0.007\end{array}$ & $\begin{array}{c}2.09(1.08-4.04), \\
p=0.028\end{array}$ & $\begin{array}{c}1.45(0.73-2.90), \\
p=0.283\end{array}$ \\
$\begin{array}{c}\text { (FGFR2high as } \\
\text { reference) }\end{array}$ & $\begin{array}{c}2.22(1.25-3.93), \\
p=0.006\end{array}$ & $\begin{array}{c}1.92(1.03-3.56), \\
p=0.038\end{array}$ & $\begin{array}{c}1.25(0.66-2.37), \\
p=0.496\end{array}$ \\
\hline
\end{tabular}


(a)

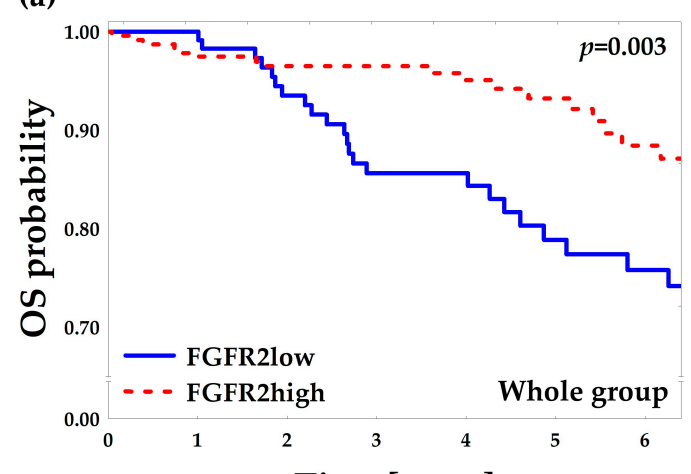

Time [years]

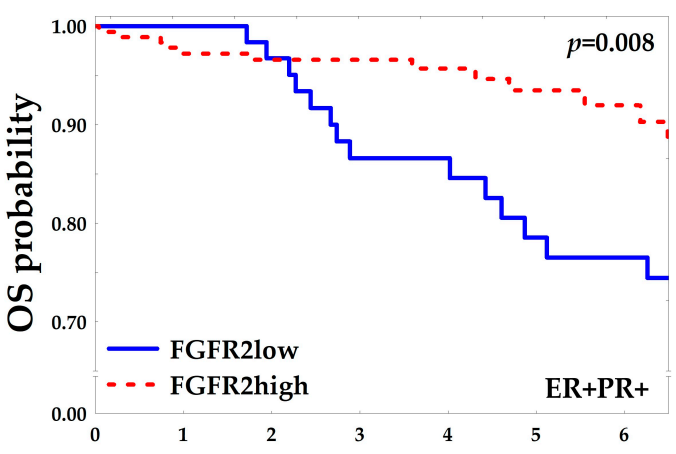

(e)

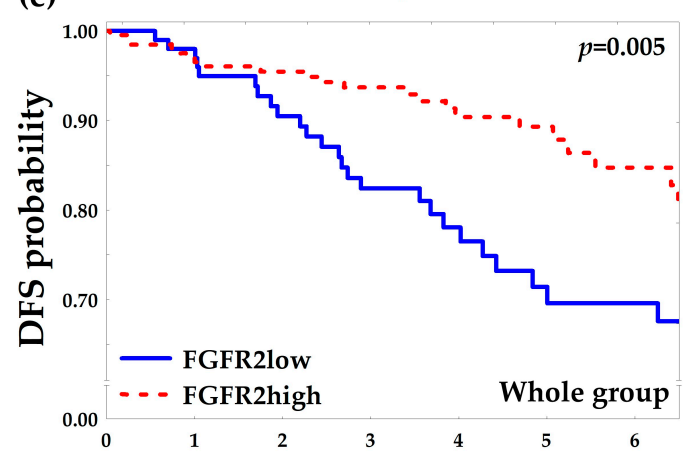

(g)

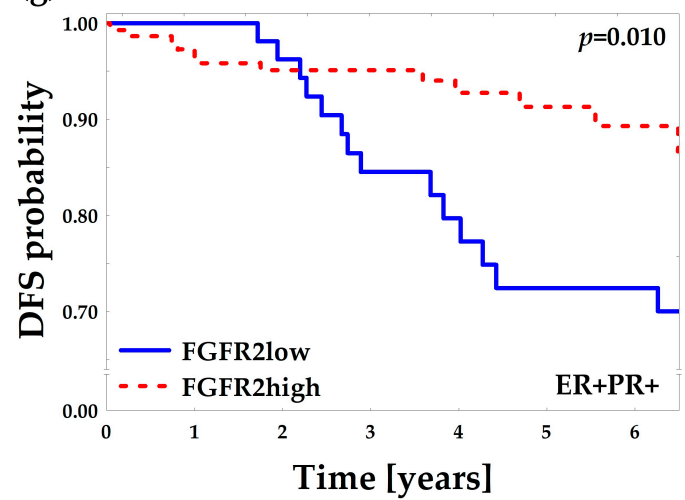

(b)

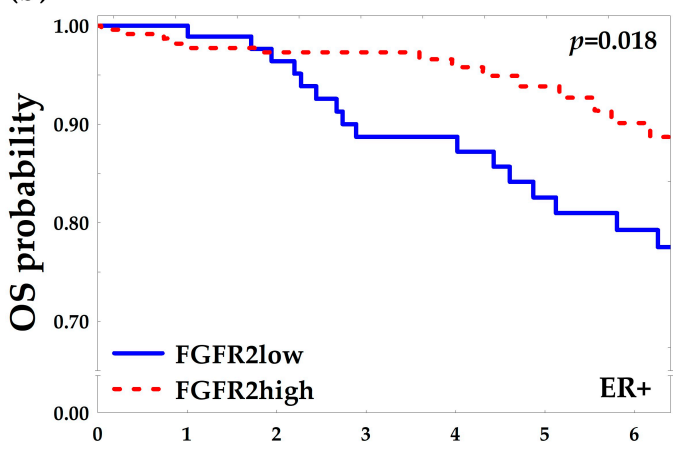

(d)

Time [years]

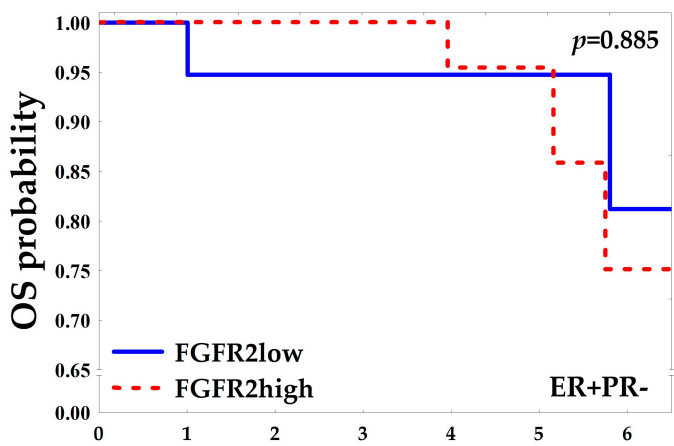

(f)

Time [years]

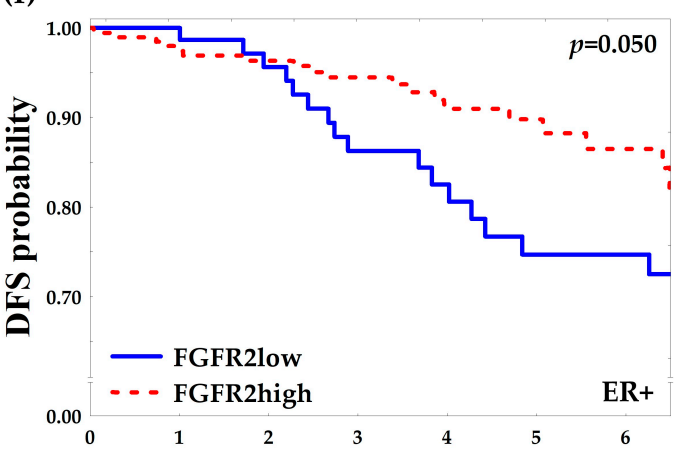

(h)

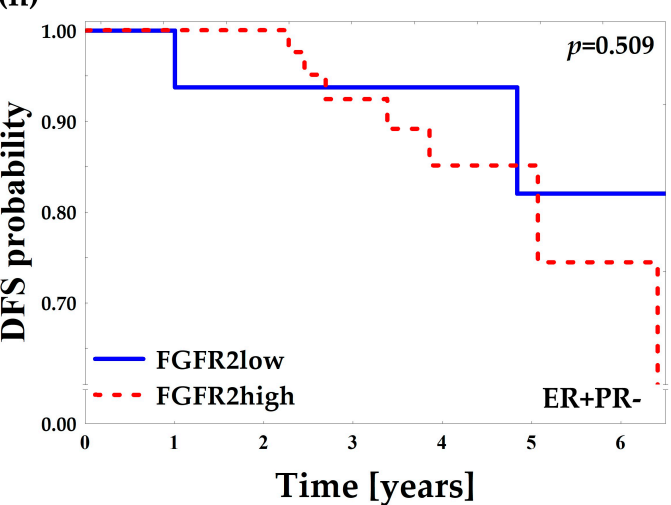

Figure 4. Kaplan-Meier curves for overall survival (OS) and disease-free survival (DFS) probability regarding FGFR2low and FGFR2high patients (divided by 1st tercile of FGFR2 H-score). "ER+" subgroup included all ER+ patients regardless of PR status and it comprised ER+PR+ and ER+PRsubgroups. $p$-values were calculated using log-rank test. (a) OS in the whole group; (b) OS in the ER+ group; (c) OS in ER+PR+ group; (d) OS in ER+PR- group; (e) DFS in the whole group; (f) DFS in the $\mathrm{ER}+$ group; (g) DFS in the ER+PR+ group; (h) DFS in the ER+PR- group. 
Reliable follow-up data for disease-free survival was available for 304 (86.1\%) of patients and the median disease-free survival was 3.9 years (IQR: 2.7-6.4) with 47 (15.4\%) events in the group. The poor prognostic impact on DFS was displayed for age, high grade, negative hormonal receptor status, larger tumor size, and lymph node metastases (Table S2). FGFR2low patients displayed poorer DFS when compared to FGFR2high patients and this effect was significant for all patients ( $p=0.005$, Figure $4 \mathrm{e})$, $\mathrm{ER}+$ patients $(p=0.050$, Figure $4 \mathrm{f})$ and $\mathrm{ER}+\mathrm{PR}+$ patients $(p=0.010$, Figure $4 \mathrm{~g})$, while nonsignificant for ER+PR- patients ( $p=0.509$, Figure $4 \mathrm{~h}$ ). In the multivariate analysis, FGFR2low showed poor prognostic impact on DFS regardless of the hormonal receptor status (HR $=1.92$ (95\% CI: 1.03-3.56)) but, as for OS, the effect was not significant when adjusted to other significant DFS variables from the univariate analyses (Table 3 and Table S2).

\subsection{Subclassification of ER+ Patients by PR(mol) Supports Association of PR-Negativity with Unfavorable Clinicopathological Characteristics}

To account for "false" negative PR tumors with undetectable PR at the protein level (due to hormone-independent activation and a rapid turnover of PR), but with effective PR transcriptional activity, a molecular signature reflecting activation of PR-dependent genes (PR(mol)-not PR protein/mRNA status) was developed [12,17,29]. Identification of the 'signature genes' was based on the bioinformatic findings of the differences in RNAseq expression levels between $\mathrm{ER}+\mathrm{PR}+, \mathrm{ER}+\mathrm{PR}-$, and ER-PR- BCa cases (ER-PR+ BCa category, as extremely rare and controversial, was not included), which were supported by reported in the literature functional associations between PR and its target genes $[12,17,29]$. RNA expression of 19 gene-candidates for the PR(mol) was evaluated: ACOT6, BIRC3, CEPBD, EP400, F3, FKBP5, GAS6, HSD11B2, KLF4, NEDD4, NET1, RASGRP4, RASSF2, RGS2, S100, SIAH2, SLC39A14, STAT5A, UCK2, the measurement of which was complemented by assessment of PGR and FGFR 2 and three housekeeping genes. The list of genes together with the criteria for inclusion are presented in the Table S3.

For four genes' (SIAH2, PGR, BIRC3, UCK2) differences in mRNA level were significantly dependent solely on the PR-status (the essential criterion for the selection), i.e., mRNA of these genes varied significantly between $\mathrm{ER}+\mathrm{PR}+$ versus $\mathrm{ER}+\mathrm{PR}-$, and between $\mathrm{ER}+\mathrm{PR}+$ versus $\mathrm{ER}-\mathrm{PR}-$ cases, but not between ER+PR- versus ER-PR- patients (used as a reference for lack of PR activity). The tree (joining) hierarchical clustering confirmed strong correlation between PGR and SIAH2 mRNA (Figure S2). Next, k-means clustering was used to design gene signature deemed to reflect activity of PR. Thus, the final PR(mol) involved expression of four genes (SIAH2, PGR, BIRC3, UCK2). Reclassification of the whole group by the PR(mol) status showed that no patients with ER-PR- BCa were allocated $\mathrm{PR}(\mathrm{mol}+)$ (Table 4, Figure 1), implying potential functional significance of $\mathrm{PR}(\mathrm{mol})$ only in ER+ patients (Table 4). Accordingly, ER+ BCa (both ER+PR+ and ER+PR-) patients were further subclassified into $\mathrm{PR}(\mathrm{mol}+)$ and $\mathrm{PR}(\mathrm{mol}-)$ categories characterized by elevated or decreased expression levels of signature genes, respectively. This resulted in $10(13.7 \%) \mathrm{ER}+\mathrm{PR}-$ patients described as $\mathrm{PR}(\mathrm{mol}+)$ and $47(19.4 \%) \mathrm{ER}+\mathrm{PR}+$ patients as PR(mol-) (Table 4$)$.

Table 4. Reclassification of cases using the PR-molecular signature (PR(mol)). Data presented as numbers and percentages in brackets. ER-estrogen receptor status, $\mathrm{PR}$ - progesterone receptor; $p<0.001$, Pearson's chi-squared test.

\begin{tabular}{ccc}
\hline Hormonal Status & PR(mol+) & PR(mol-) \\
\hline ER-PR- & $0(0.0 \%)$ & $32(100.0 \%)$ \\
ER+PR- & $10(13.7 \%)$ & $63(86.3 \%)$ \\
ER+PR+ & $194(80.6 \%)$ & $47(19.4 \%)$ \\
All & $204(59.1 \%)$ & $142(40.9 \%)$ \\
\hline
\end{tabular}

$\mathrm{PR}(\mathrm{mol}+)$ and $\mathrm{PR}(\mathrm{mol}-)$ tumors were analyzed in relation to the pathological and clinical features (Table S4). The results showed associations between poor prognostic features and allocation into 
PR(mol-) subgroup. PR(mol-) tumors were characterized by higher grade $(p=0.039)$ and Ki67 index $(p=0.003)$, more frequent HER2 amplification $(p=0.002)$, and larger size $(p=0.007)$ when compared to $\mathrm{PR}(\mathrm{mol}+)$ patients. In survival analyses, $\mathrm{PR}(\mathrm{mol}-)$ patients did not display poorer OS or DFS in comparison to $\mathrm{PR}(\mathrm{mol}+)$ patients $(p=0.551$ and $p=0.354$, respectively, Table S4).

\subsection{PR(mol) Status Does Not Affect Prognostic Value of FGFR2}

FGFR2 protein level did not differ significantly between $\mathrm{PR}(\mathrm{mol}+)$ and $\mathrm{PR}(\mathrm{mol}-)$ patients $(p=0.739)$, while FGFR2 gene mRNA was significantly higher in $\mathrm{PR}(\mathrm{mol}+)$ than $\mathrm{PR}(\mathrm{mol}-)$ cases $(p=0.008$, Figure 5 and Figure S3, Table S5). Associations of FGFR2low with high grade and high Ki67 proliferation index, described above, were independent of PR(mol) (Table S6). Similarly, poor prognostic impact of FGFR2low on DFS and OS was found not to depend on PR(mol) (Table S6).

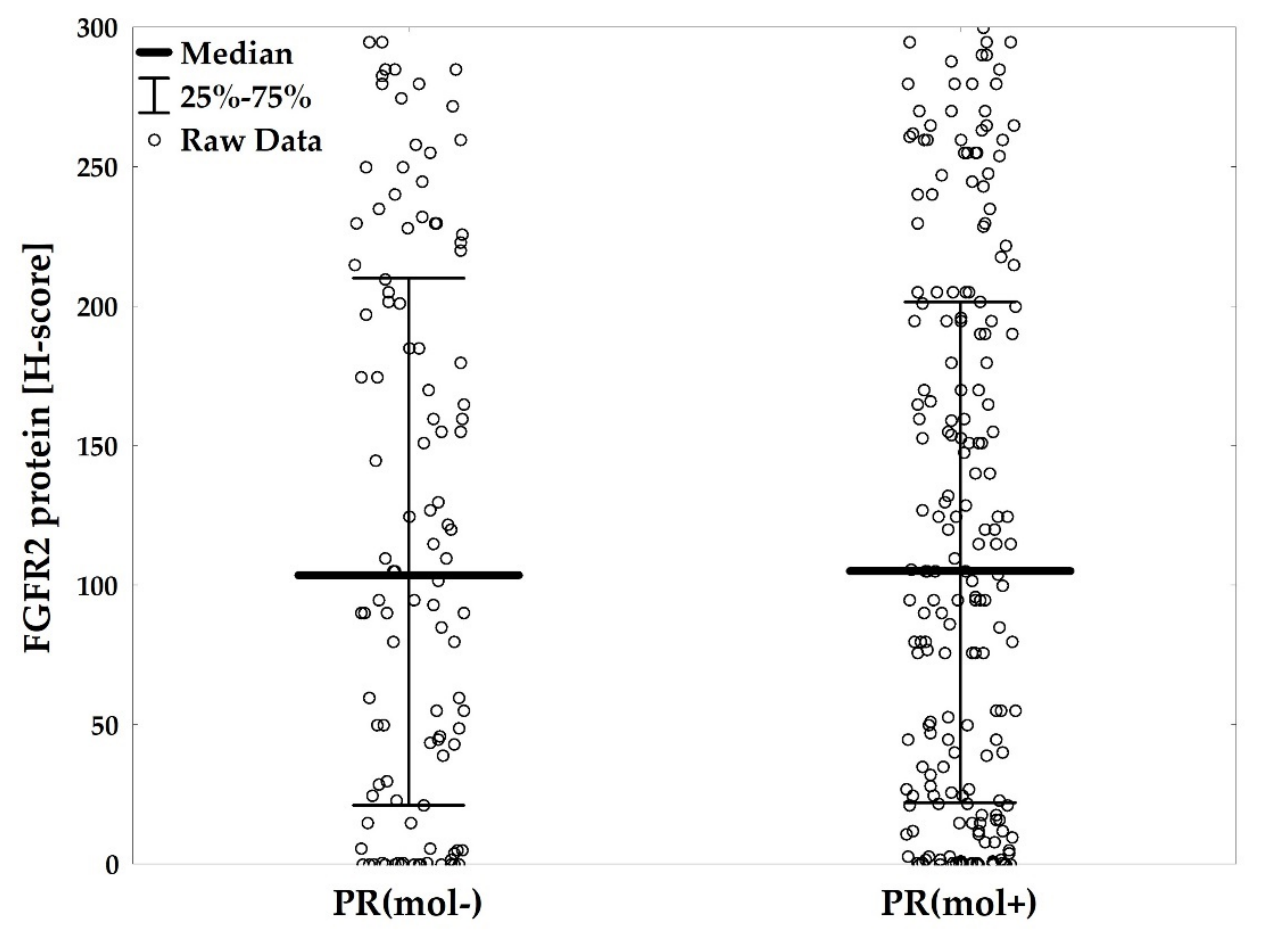

Figure 5. FGFR2 protein levels (H-score) compared regarding progesterone receptor molecular activity status $(\mathrm{PR}(\mathrm{mol}-)$ vs. $\mathrm{PR}(\mathrm{mol}+)), p<0.001$. $p$-values from Kruskal-Wallis ANOVA test.

2.5. Low FGFR2 Gene mRNA Level Is Associated with Poor Overall and Relapse-Free Survival—In Silico Confirmation

Prognostic significance of FGFR2 was verified in silico. Out of 2509 BCa patients from the METABRIC-TCGA database [30,31], 1242 fulfilled the requirements of the study, i.e., invasive ductal carcinoma of no special type (IDC, NST), available data on follow-up, FGFR2 gene mRNA, and hormonal receptor status, and were selected for the analysis (Figure S4). Overall survival was compared between FGFR2low versus FGFR2high patients (divided by 1st tercile of FGFR2 gene mRNA, Figure 6a-d). The poorer OS of FGFR2low than FGFR2high cases was apparent in all patients and in the ER+PR+ subgroup (Gehan-Wilcoxon $p<0.001$, Figure 6 a and $p=0.023$ Figure $6 c$, respectively), supporting our data presented in Figure 4. However, in the ER+PR- group, FGFR2high patients tended to display poorer OS than FGFR2low cases (Gehan-Wilcoxon $p=0.066$, Figure $6 \mathrm{~d}$ ). A possible overwriting effect of FGFR2 gene alterations (especially activating mutations/amplification) on poor survival was considered by accession for data on genetic alterations. However, FGFR2 gene amplification or point mutation were found in only 24 out of $1636(1.47 \%)$ invasive ductal carcinoma of no special type 
(IDC, NST) patients and had no effect on overall survival (log-rank $p=0.170$ ). No DFS data were accessible through the TCGA database.

(a)

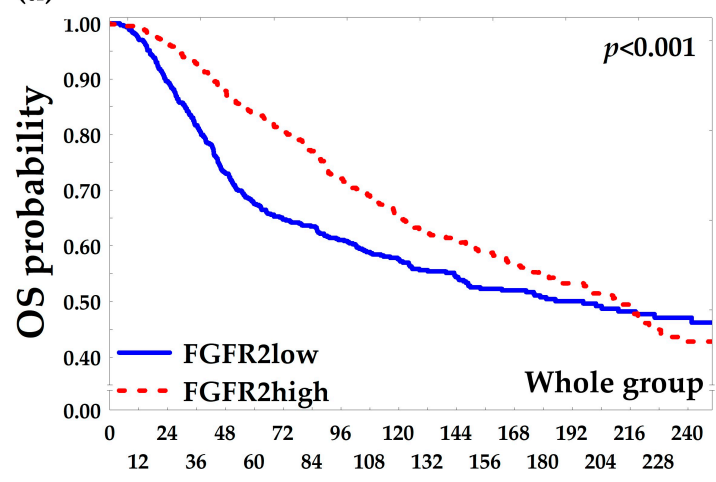

(c)

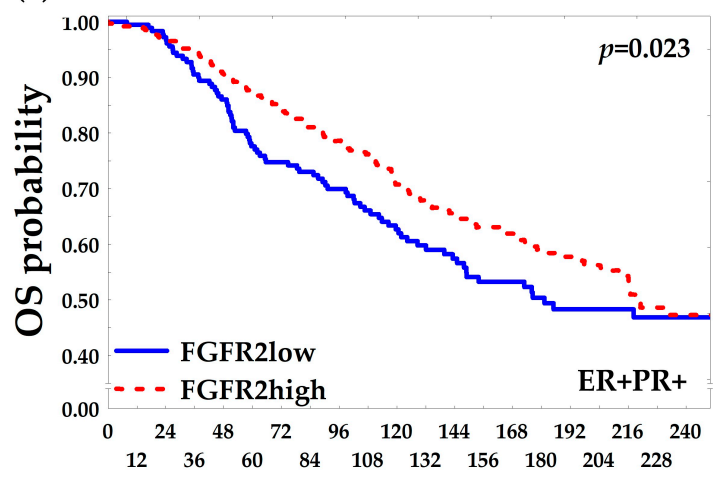

Time [months] (b)

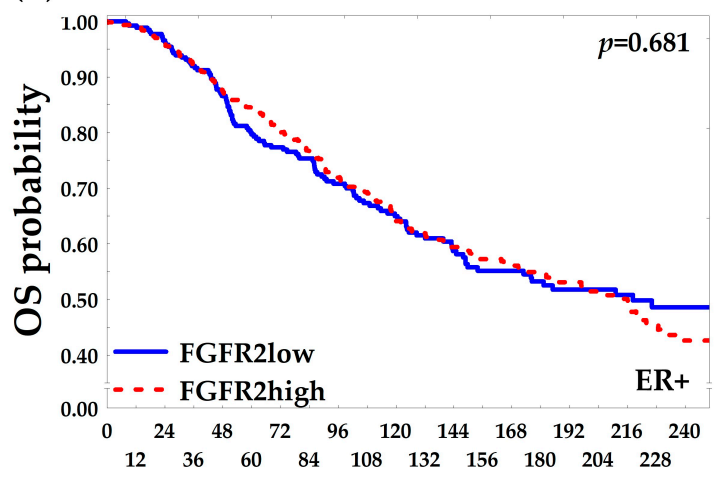

(d)

Time [months]

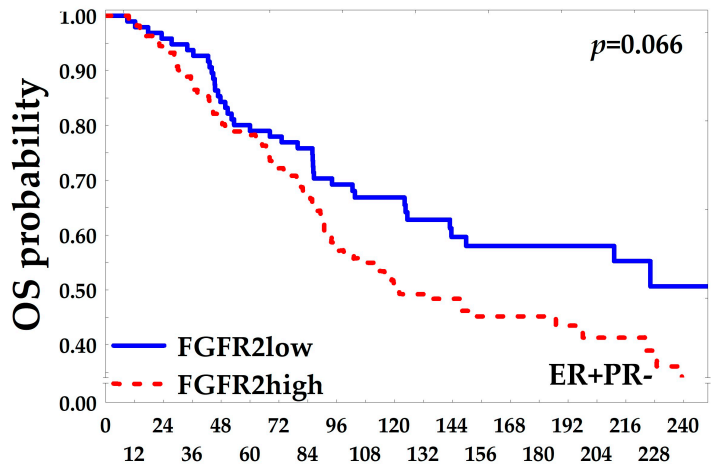

Time [months]

Figure 6. Kaplan-Meier curves for overall survival (OS) probability regarding levels of FGFR2 gene mRNA. METABRIC-TCGA data were accessed from cBioPortal. Invasive ductal carcinoma of no special type samples were divided into FGFR2low and FGFR2high subgroups by 1st tercile of FGFR2 gene mRNA (1st tercile for FGFR2low, 2nd and 3rd terciles for FGFR2high patients). "ER+" subgroup included all $\mathrm{ER}+$ patients regardless of PR status and it comprised $\mathrm{ER}+\mathrm{PR}+$ and $\mathrm{ER}+\mathrm{PR}-$ subgroups. Due to long observation $p$-values were calculated using Gehan's Wilcoxon test. (a) OS in the whole group $(n=1242) ;(\mathbf{b})$ OS in the ER+ group $(n=1070) ;(\mathbf{c})$ OS in the ER+PR+ group $(n=720) ;(d)$ OS in the ER+PR- group $(n=350)$.

In a complementary approach, an impact of FGFR2 gene mRNA levels (microarray data) on OS of 1402 BCa patients (other than considered in the TCGA database, Figure S4) meeting inclusion criteria of this study was estimated by the Kaplan-Meier plotter [32]. The FGFR2low patients $(<1$ st tercile of mRNA level) showed worse overall survival compared to FGFR2high patients (HR 1.82 (95\% CI: 1.40-2.40), $p<0.001$; Figure S5a). This poor prognostic effect was mostly apparent for ER+ patients (HR 1.96 (95\% CI: 1.30-3.00), $p<0.001$; Figure S5b), while PR status did not affect OS in the group (likely due to low number of cases with reported PR status, Figure S5c,d). DFS data along with FGFR2 gene mRNA from the same database was accessible for 3951 BCa cases. Similarly to OS, FGFR2low patients displayed poor prognostic effect when compared to FGFR2high patients (HR 1.54 (95\% CI: $1.30-1.80), p<0.001$, Figure S5e). This effect was also apparent in both ER+ and ER+PR+ subgroups $(p<0.001$ and $p=0.002$, respectively, Figure S5f-g), but not in ER+PR- patients ( $p=0.363$, Figure S5h).

\section{Discussion}

In contrast to the reported functional association between FGFR2 and resistance to anti-ER treatment in $\mathrm{BCa}$, our results suggested that lack or low expression of FGFR2 is characteristic of 
hormone receptor-negative and poorly differentiated tumors, and is prognostic for poor survival, regardless of the transcriptional activity of PR. This finding was confirmed across two external open access databases encompassing almost $5000 \mathrm{BCa}$ patients, as well as in the multivariate analyses.

The deleterious crosstalk between FGFR2 and ER/PR signaling in BCa has been robustly documented in mechanistic studies, but supporting observations from the clinic are still lacking $[4,5]$. FGFR2 acts as an essential regulator of steroid hormone receptors activity by several, likely independent mechanisms, i.e., interaction with ER (shifting ER binding to DNA) and/or hormone-independent activation and rapid degradation of the receptors $[5,9,15]$. Noncanonical hyperactivation of PR and alteration of its molecular communication with ER (reviewed in [5]) have been shown to strongly promote hormone independence and resistance to anti-ER therapies. These effects are associated with a rapid turnover/degradation of the PR protein, which is undetectable by immunohistochemistry, routinely used to assess ER/PR protein levels ("concealed positivity") [13-15]. These were the premises for the presented analyses of the prognostic value of FGFR2 expression in the context of not only ER and PR protein status, but also PR transcriptional activity.

In contrast to the postulated relationship between high FGFR2 and poor prognosis, we found that worse overall and disease-free survival of BCa patients was associated with low FGFR2 expression on both protein and mRNA levels. Moreover, low FGFR2 was also associated with prognostically unfavorable tumor characteristics, i.e., high proliferation index and poor differentiation, which may suggest that in certain biological settings, tumor aggressiveness might be featured or enforced by low FGFR2. Although there has been no clear mechanistic explanation for this adverse effect of FGFR2 loss, available data support a differential, context-dependent prognostic value of FGFR2. For example, high FGFR2 expression has been recently shown to correlate with increased $\mathrm{BCa}$ sensitivity to endocrine therapy combined with inhibitors of CDK4/6 [33]. Loss of function mutations in FGFR2 gene contributed to melanoma progression, whilst gain of function alterations were reported to promote growth of endometrial carcinoma [34-36]. Conditional FGFR2 gene knockout and low or reduced FGFR2 expression were linked with increased sensitivity to chemically induced squamous cell carcinoma of the skin [37], more aggressive growth of hepatocellular carcinoma [38], and increased epithelial-to-mesenchymal transition [39].

Our results confirmed the tight link between FGFR2 expression and the ER/PR status, showing that low FGFR2 is characteristic of ER-PR- tumors. Furthermore, the poor prognostic effect of low FGFR2 was found to be lost in ER+PR- patients. Although the assumed 'concealed positivity' of PR induced by FGFR2 has a solid biological background [18-20], our data fail to support it. The designed signature deemed to reflect transcriptional activity of PR and, when used for subclassification of patients with ER+ tumors, maintained poor prognostic effect of PR-negativity. However, the impact of FGFR2 on patients' survival was found to be independent of the status determined by the PR signature. This may suggest that a functional relationship between FGFR2 and PR is likely to be influenced by additional factors, including interaction with ER, identification of which in vivo remains notoriously difficult and requires much more comprehensive molecular evaluation.

The major limitation of our clinical analyses concerns incomplete data on relapse and progression in $15 \%$ of patients of the study group. Even though the guidelines for BCa treatment care are consistent throughout the EU, many patients undergo specific procedures at different locations, which significantly hinders identification of progression and relapses. Of note, distribution of hormonal receptor subgroups in our cohort was similar to the worldwide reports [40]. The external validation of our findings in the TCGA and KM-plotter databases, which accounted for FGFR2 gene mRNA and importantly for genetic alterations in FGFR2 gene, diminished the possible effect of this limitation. 


\section{Materials and Methods}

\subsection{Patient Selection and Collection of Histopathological and Clinical Data}

Formalin-fixed, paraffin-embedded (FFPE) tumoral tissue of invasive breast carcinoma, of no special type (IDC, NST) was collected from 353 patients treated at the Regional Oncologic Centre of Copernicus Memorial Hospital, Lodz, Poland and at the Holycross Cancer Centre, Kielce, Poland, between 2004 and 2018. Initial diagnoses were confirmed on hematoxylin/eosin (H\&E) stained sections. Patient characteristics (in accordance with the WHO 2012 and 2019 classification of BCa [41]) are presented in Table 1. Statuses of ER and PR were determined according to the Allred scoring system [42]. "ER+" subgroup included all ER+ patients regardless of PR status and it comprised $\mathrm{ER}+\mathrm{PR}+$ and $\mathrm{ER}+\mathrm{PR}-$ subgroups. HER2 status was defined using Herceptest ${ }^{\mathrm{TM}}$ (Agilent, Santa Clara, CA, USA) and FISH, whereas Ki67 index was assessed according to the guidelines applicable at the time of diagnosis $[43,44]$. The study was approved by the Local Research Ethics Committee (No. RNN/34/16/KE).

\subsection{Immunohistochemistry for FGFR2}

Immunohistochemical staining (IHC) for FGFR2 in all tumors was conducted using a mouse monoclonal anti-FGFR2 antibody (H00002263-M01; clone 1G3, Abnova, Heidelberg, Germany) (Figure 2). To confirm specificity of the staining, additional IHC with a mouse anti-FGFR2 antibody (Sc-6930, Santa Cruz, CA, USA) was performed in randomly selected samples. Following manufacturer's recommendations, tissue samples of gastric adenocarcinoma and lymph node were used as positive and negative controls for IHC, respectively. Immunohistochemical procedures were carried out on 5- $\mu \mathrm{m}$ paraffin sections, as reported previously $[9,15]$. All slides were digitalized using Pannoramic 1000 Scanner (3DHistech, Sysmex, Kobe, Japan). FGFR2 levels were quantified according to the semiquantitative $\mathrm{H}$-score approach by two independent pathologists $(\mathrm{MB}, \mathrm{HR})$. The data were presented in 0-300 scale resulting from multiplication of percentage of positive cells by intensity of staining: 0-no staining, 1-3-increased intensity of both cytoplasmic and membrane staining (subgroups by H-score: 0-75 for negative/weak; 76-150 for moderate; 151-225 for strong; 226-300 for very strong expression) (Figure 2). Cases from 1st tercile of H-score were regarded as FGFR2low and cases from 2nd and 3rd terciles were classified as FGFR2high.

\subsection{RNA Quantification}

For RNA quantification, representative tumoral FFPE samples from areas with no necrosis, fibrosis, or calcification were selected and dissected. RNA was isolated using RNeasy FFPE Kit (Qiagen, Hilden, Germany) followed by quality control on Tapestation 2200 (Agilent, Santa Clara, CA, USA). Quantification of RNA was done by Nanostring ${ }^{\circledR}$ company using nCounter PlexSet Expression analysis (Seattle, WA, USA) [45,46]. RNA counts were normalized using nSolver ${ }^{\circledR}$ Analysis package (Nanostring, Seattle, WA, USA). Four negative controls (normal breast gland) and 16 internal controls (two samples of the same tumor; $n=5$ and RNA measurement in duplicates, $n=3$ ) were applied.

\subsection{In Silico Analysis of TCGA Data}

The Cancer Genome Atlas (TCGA) Research Network (https://www.cancer.gov/tcga) was accessed for RNAseq data of BCa samples with both ER and PR statuses reported. The counts were normalized for GC-content effect and gene length using less robust local regression, global-scaling, and full-quantile normalization. The first quantile (0.25) mean across all samples was used as the threshold in filtering transcripts. Differential expression analysis between ER+PR+ and ER-PR- patients was performed by fitting the linear model and computation moderated t-statistics, moderated F-statistic, and log-odds of differential expression by empirical Bayes moderation of the standard errors towards a common value. Based on $p$-values, genes/candidates with the most significant differences in the level of expression were identified and, considered to reflect transcriptional activity of PR, were collectively named 
'the PR-signature' (called PR(mol)). R software was utilized in the analysis (packages: TCGAbiolinks, EDASeq, limma). Relevant clinical and pathological data were matched to allow comparative analysis of the findings from our study group with other representative datasets.

\subsection{Statistical Analysis}

Continuous data was presented as medians with interquartile ranges (IQR), whereas nominal data as numbers followed by percentages in brackets. After evaluation of distribution's normality using the Shapiro-Wilk test, continuous variables were compared by the Mann-Whitney $U$-test for two groups or the Kruskal-Wallis test (AKW; with Conover-Inman post-hoc test) for multiple groups, in case of non-normal distribution. In case of normal distribution, Student's $t$-test or one-/two-way block ANOVA (with Tukey's post-hoc test) were used. Differences between categorical variables were evaluated using the Pearson's chi-squared test. The Spearman's rank correlation coefficients were calculated for correlations. Benjamini-Hochberg $(\mathrm{BH})$ correction in case of multiple comparisons was applied. For development of PR-signature, k-means clustering with Euclidean distances between clusters, and hierarchical clustering with 1-R for linkage distance reporting were applied. Disease-free survival (DFS, the time from surgery to relapse, progression or death with censoring of living patients) and overall survival (OS, the time from diagnosis to death with censoring of living patients) were presented using Kaplan-Meier curves, and compared using the log-rank test unless noted otherwise [47]. A multivariate analysis of OS and DFS was performed using Cox's proportional hazard regression models. The Statistica 13.1 package (Dell Inc., Round Rock, TX, USA) was used. $p$-values $<0.05$ were considered as statistically significant.

\section{Conclusions}

In summary, our data show that, in contrast to the previously reported link between increased activity of FGFR2 and resistance to anti-ER therapies, low expression of FGFR2 is associated with poor prognosis in BCa. These findings indicate a multifactorial regulation of the FGFR2-ER/PR crosstalk and may provide, at least partially, an explanation for unsatisfactory results of clinical trials of FGFR inhibitors in BCa as well as open new avenues for the study of complexity of FGFR2 role in BCa pathogenesis.

Supplementary Materials: The following are available online at http://www.mdpi.com/2072-6694/12/9/2713/s1. Figure S1: FGFR2 mRNA levels compared between hormonal receptor status subgroups (ER-PR- vs. ER+PRvs. ER+PR+), $p=0.049$ from ANOVA test, Figure S2: Hierarchical tree-clusterization of genes included in PR-dependent molecular signature. All patients with good quality RNA were included in this analysis. Linkage distance is showed as 1-R (Spearman), Figure S3: FGFR2 mRNA levels compared between estrogen receptor status and progesterone receptor molecular activity status (ER-PR (mol-) vs. ER+PR (mol-) vs. ER+PR $(\mathrm{mol}+)), p=0.002$. $p$-value from ANOVA test, Figure S4: Flowchart of the in silico verification with indication of numbers of patients from the external databases included in every analysis. "ER+" subgroup included all $\mathrm{ER}+$ patients regardless of PR status and it comprised ER+PR+ and ER+PR- subgroups. IDC, NST-invasive ductal carcinoma of no special type, ER - estrogen receptor protein status, $\mathrm{PR}$ - progesterone receptor protein status, FGFR2-fibroblast growth factor receptor 2 protein, Figure S5: Kaplan-Meier curves for OS (a-d) and PFS (e-h) regarding FGFR2 microarray mRNA levels. "ER+" subgroup included all ER+ patients regardless of PR status and it comprised ER+PR+ and ER+PR- subgroups. FGFR2low stands for 1st tercile and FGFR2high for 2nd and 3rd terciles. Plots were generated using online open access tool KM plotter (encompassing patients different than those included in TCGA database). (a) OS probability in all 1402 breast cancer patients, (b) OS probability in all 548 ER+ breast cancer patients, (c) OS probability in all 76 ER+PR+ patients, (d) OS probability in all 25 ER+PR- patients, (e) PFS probability in all 3951 breast cancer patients, (f) PFS probability in all 2061 ER+ breast cancer patients, (g) PFS probability in all $559 \mathrm{ER}+\mathrm{PR}+$ patients, (h) PFS probability in all $154 \mathrm{ER}+\mathrm{PR}-$ patients, Table S1: Expression of FGFR2 protein and mRNA in relation to ER/PR status. Nominal variables are presented as raw values followed by percentages of the respective groups, continuous variables are presented as medians and interquartile ranges in brackets, Table S2: Cox univariate and multivariate overall and disease-free survival analyses according to prognostic clinicopathological features, including FGFR2 status (low vs. high divided by 1 st tercile of protein $\mathrm{H}$-score). Hazard ratios are present for nominal variables, while $\beta$-parameters for continuous variables. Variables significant only in univariate analyses were incorporated in multivariate analyses. CI—confidence interval, NA—not applicable, Table S3: List of PR-dependent genes (PR (mol)—“molecular signature") signifying receptor activation and rapid degradation with respective reasons for inclusion, Table S4: Clinical and pathological characteristics of PR (mol-) versus PR (mol+) subgroups within ER+ patients. Nominal 
variables are presented as raw values followed by percentages of the respective groups, continuous variables are presented as medians and interquartile ranges in brackets, Table S5: Expression of FGFR2 protein and mRNA in PR (mol-) versus PR (mol+) patients within ER+ subgroup. Nominal variables are presented as raw values followed by percentages of the respective groups, continuous variables are presented as medians and interquartile ranges in brackets, Table S6: Multivariate analyses of the combined effect of FGFR2 (protein) status and PR(mol) status on the poor prognostic associations characterized for FGFR2(low). The analysis involves only ER+ patients. Hazard ratios with confidence intervals are present for overall and disease-free survival, $\beta$-parameters, and standard deviation for Ki67 proliferation index and odds ratios (OR) with confidence intervals for tumor grade.

Author Contributions: Conceptualization, M.B., R.S. and H.M.R.; Data curation, M.B., D.P., K.S. and A.Z.; Formal analysis, M.B., B.T. and K.S.; Funding acquisition, R.K., R.S. and H.M.R.; Investigation, M.B., D.P., K.M. and A.Z.; Methodology, M.B., D.P., B.T. and K.S.; Project administration, R.K., R.S. and H.M.R.; Resources, M.B., J.K., D.N. and R.K.; Software, B.T. and K.S.; Supervision, R.K., R.S. and H.M.R.; Validation, M.B.; Visualization, M.B., D.P. and B.T.; Writing—original draft, M.B., R.S. and H.M.R.; Writing-review and editing, M.B., D.P., B.T., K.M., K.S., A.Z., J.K., D.N., R.K., R.S. and H.M.R. All authors have read and agreed to the published version of the manuscript.

Funding: This research was funded by Polish National Science Centre, grant numbers: OPUS UMO-2015/17/B/NZ4/02157, OPUS UMO-2017/27/B/NZ3/01474, SONATA BIS no. UMO-2018/30/E/NZ3/00222.

Acknowledgments: We thank Sysmex Poland (Mateusz Bobrowski) for providing access to Pannoramic 1000 and 3DHistech software. Marcin Braun and Bartlomiej Tomasik gratefully acknowledge the financial support provided by the Foundation for Polish Science.

Conflicts of Interest: The authors declare no conflict of interest.

\section{References}

1. Place, A.E.; Jin Huh, S.; Polyak, K. The microenvironment in breast cancer progression: Biology and implications for treatment. Breast Cancer Res. 2011, 13, 227. [CrossRef] [PubMed]

2. Balkwill, F.R.; Capasso, M.; Hagemann, T. The tumor microenvironment at a glance. J. Cell Sci. 2012, 125, 5591-5596. [CrossRef] [PubMed]

3. Osborne, C.K.; Schiff, R. Mechanisms of Endocrine Resistance in Breast Cancer. Annu. Rev. Med. 2011, 62, 233-247. [CrossRef]

4. Babina, I.S.; Turner, N.C. Advances and challenges in targeting FGFR signalling in cancer. Nat. Rev. Cancer 2017, 17, 318-332. [CrossRef]

5. Piasecka, D.; Braun, M.; Kitowska, K.; Mieczkowski, K.; Kordek, R.; Sadej, R.; Romanska, H. FGFs/FGFRs-dependent signalling in regulation of steroid hormone receptors-implications for therapy of luminal breast cancer. J. Exp. Clin. Cancer Res. 2019, 38, 230. [CrossRef]

6. Campbell, T.M.; Castro, M.A.A.; de Santiago, I.; Fletcher, M.N.C.; Halim, S.; Prathalingam, R.; Ponder, B.A.J.; Meyer, K.B. FGFR2 risk SNPs confer breast cancer risk by augmenting oestrogen responsiveness. Carcinogenesis 2016, 37, 741-750. [CrossRef]

7. Campbell, T.M.; Castro, M.A.A.; De Oliveira, K.G.; Ponder, B.A.J.; Meyer, K.B. ER $\alpha$ Binding by Transcription Factors NFIB and YBX1 Enables FGFR2 Signaling to Modulate Estrogen Responsiveness in Breast Cancer. Cancer Res. 2018, 78, 410-421. [CrossRef]

8. Giulianelli, S.; Cerliani, J.P.; Lamb, C.A.; Fabris, V.T.; Bottino, M.C.; Gorostiaga, M.A.; Novaro, V.; Góngora, A.; Baldi, A.; Molinolo, A.; et al. Carcinoma-associated fibroblasts activate progesterone receptors and induce hormone independent mammary tumor growth: A role for the FGF-2/FGFR-2 axis. Int. J. Cancer 2008, 123, 2518-2531. [CrossRef]

9. Piasecka, D.; Kitowska, K.; Czaplinska, D.; Mieczkowski, K.; Mieszkowska, M.; Turczyk, L.; Skladanowski, A.C.; Zaczek, A.J.; Biernat, W.; Kordek, R.; et al. Fibroblast growth factor signalling induces loss of progesterone receptor in breast cancer cells. Oncotarget 2016, 7, 86011-86025. [CrossRef]

10. Cerliani, J.P.; Guillardoy, T.; Giulianelli, S.; Vaque, J.P.; Gutkind, J.S.; Vanzulli, S.I.; Martins, R.; Zeitlin, E.; Lamb, C.A.; Lanari, C. Interaction between FGFR-2, STAT5, and progesterone receptors in breast cancer. Cancer Res. 2011, 71, 3720-3731. [CrossRef]

11. Musgrove, E.A.; Sutherland, R.L. Biological determinants of endocrine resistance in breast cancer. Nat. Rev. Cancer 2009, 9, 631-643. [CrossRef] [PubMed]

12. Daniel, A.R.; Knutson, T.P.; Lange, C.A. Signaling inputs to progesterone receptor gene regulation and promoter selectivity. Mol. Cell Endocrinol. 2009, 308, 47-52. [CrossRef] [PubMed] 
13. McLeskey, S.W.; Zhang, L.; El-Ashry, D.; Trock, B.J.; Lopez, C.A.; Kharbanda, S.; Tobias, C.A.; Lorant, L.A.; Hannum, R.S.; Dickson, R.B.; et al. Tamoxifen-resistant fibroblast growth factor-transfected MCF-7 cells are cross-resistant in vivo to the antiestrogen ICI 182,780 and two aromatase inhibitors. Clin. Cancer Res. 1998, 4, 697-711. [PubMed]

14. Lupien, M.; Meyer, C.A.; Bailey, S.T.; Eeckhoute, J.; Cook, J.; Westerling, T.; Zhang, X.; Carroll, J.S.; Rhodes, D.R.; Liu, X.S.; et al. Growth factor stimulation induces a distinct ER(alpha) cistrome underlying breast cancer endocrine resistance. Genes Dev. 2010, 24, 2219-2227. [CrossRef] [PubMed]

15. Turczyk, L.; Kitowska, K.; Mieszkowska, M.; Mieczkowski, K.; Czaplinska, D.; Piasecka, D.; Kordek, R.; Skladanowski, A.C.; Potemski, P.; Romanska, H.M.; et al. FGFR2-Driven Signaling Counteracts Tamoxifen Effect on ERalpha-Positive Breast Cancer Cells. Neoplasia 2017, 19, 791-804. [CrossRef]

16. Daniel, A.R.; Faivre, E.J.; Lange, C.A. Phosphorylation-dependent antagonism of sumoylation derepresses progesterone receptor action in breast cancer cells. Mol. Endocrinol. 2007, 21, 2890-2906. [CrossRef]

17. Knutson, T.P.; Daniel, A.R.; Fan, D.; Silverstein, K.A.; Covington, K.R.; Fuqua, S.A.; Lange, C.A. Phosphorylated and sumoylation-deficient progesterone receptors drive proliferative gene signatures during breast cancer progression. Breast Cancer Res. 2012, 14, 1-23. [CrossRef]

18. Drago, J.Z.; Formisano, L.; Juric, D.; Niemierko, A.; Servetto, A.; Wander, S.A.; Spring, L.M.; Vidula, N.; Younger, J.; Peppercorn, J.; et al. FGFR1 gene amplification mediates endocrine resistance but retains TORC sensitivity in metastatic hormone receptor positive (HR+) breast cancer. Clin. Cancer Res. 2019, 25, 6443-6451. [CrossRef]

19. Formisano, L.; Lu, Y.; Servetto, A.; Hanker, A.B.; Jansen, V.M.; Bauer, J.A.; Sudhan, D.R.; Guerrero-Zotano, A.L.; Croessmann, S.; Guo, Y.; et al. Aberrant FGFR signaling mediates resistance to CDK4/6 inhibitors in ER+ breast cancer. Nat. Commun. 2019, 10,1-14. [CrossRef]

20. Giltnane, J.M.; Hutchinson, K.E.; Stricker, T.P.; Formisano, L.; Young, C.D.; Estrada, M.V.; Nixon, M.J.; Du, L.; Sanchez, V.; Ericsson, P.G.; et al. Genomic profiling of ER+ breast cancers after short-term estrogen suppression reveals alterations associated with endocrine resistance. Sci. Transl. Med. 2017, 9, eaai7993. [CrossRef]

21. Mao, P.; Cohen, O.; Kowalski, K.J.; Kusiel, J.G.; Buendia-Buendia, J.E.; Cuoco, M.S.; Exman, P.; Wander, S.A.; Waks, A.G.; Nayar, U.; et al. Acquired FGFR and FGF alterations confer resistance to estrogen receptor (ER) targeted therapy in ER+ metastatic breast cancer. bioRxiv 2019. [CrossRef]

22. Lee, H.J.; Seo, A.N.; Park, S.Y.; Kim, J.Y.; Park, J.Y.; Yu, J.H.; Ahn, J.-H.; Gong, G. Low Prognostic Implication of Fibroblast Growth Factor Family Activation in Triple-negative Breast Cancer Subsets. Ann. Surg. Oncol. 2014, 21, 1561-1568. [CrossRef] [PubMed]

23. Liu, G.; Xiong, D.; Xiao, R.; Huang, Z. Prognostic role of fibroblast growth factor receptor 2 in human solid tumors: A systematic review and meta-analysis. Tumor Biol. 2017, 39. [CrossRef] [PubMed]

24. Czaplinska, D.; Mieczkowski, K.; Supernat, A.; Skladanowski, A.C.; Kordek, R.; Biernat, W.; Zaczek, A.J.; Romanska, H.M.; Sadej, R. Interactions between FGFR2 and RSK2-implications for breast cancer prognosis. Tumor Biol. 2016, 37, 13721-13731. [CrossRef] [PubMed]

25. Sadej, R.; Lu, X.; Turczyk, L.; Novitskaya, V.; Lopez-Clavijo, A.F.; Kordek, R.; Potemski, P.; Wakelam, M.J.O.; Romanska-Knight, H.; Berditchevski, F. CD151 regulates expression of FGFR2 in breast cancer cells via PKC-dependent pathways. J. Cell Sci. 2018, 131. [CrossRef] [PubMed]

26. Sun, S.; Jiang, Y.; Zhang, G.; Song, H.; Zhang, X.; Zhang, Y.; Liang, X.; Sun, Q.; Pang, D. Increased expression of fibroblastic growth factor receptor 2 is correlated with poor prognosis in patients with breast cancer. J. Surg. Oncol. 2012, 105, 773-779. [CrossRef]

27. Martin, A.J.; Grant, A.; Ashfield, A.M.; Palmer, C.N.; Baker, L.; Quinlan, P.R.; Purdie, C.A.; Thompson, A.M.; Jordan, L.B.; Berg, J.N. FGFR2 protein expression in breast cancer: Nuclear localisation and correlation with patient genotype. BMC Res. Notes 2011, 4, 72. [CrossRef]

28. Knutson, T.P.; Truong, T.H.; Ma, S.; Brady, N.J.; Sullivan, M.E.; Raj, G.; Schwertfeger, K.L.; Lange, C.A. Posttranslationally modified progesterone receptors direct ligand-specific expression of breast cancer stem cell-associated gene programs. J. Hematol. Oncol. 2017, 10, 89. [CrossRef]

29. Richer, J.K.; Jacobsen, B.M.; Manning, N.G.; Abel, M.G.; Wolf, D.M.; Horwitz, K.B. Differential gene regulation by the two progesterone receptor isoforms in human breast cancer cells. J. Biol. Chem. 2002, 277, 5209-5218. [CrossRef] 
30. Pereira, B.; Chin, S.-F.; Rueda, O.M.; Vollan, H.-K.M.; Provenzano, E.; Bardwell, H.A.; Pugh, M.; Jones, L.; Russell, R.; Sammut, S.-J.; et al. The somatic mutation profiles of 2433 breast cancers refine their genomic and transcriptomic landscapes. Nat. Commun. 2016, 7, 11479. [CrossRef]

31. Curtis, C.; Shah, S.P.; Chin, S.-F.; Turashvili, G.; Rueda, O.M.; Dunning, M.J.; Speed, D.; Lynch, A.G.; Samarajiwa, S.; Yuan, Y.; et al. The genomic and transcriptomic architecture of 2,000 breast tumours reveals novel subgroups. Nature 2012, 486, 346-352. [CrossRef] [PubMed]

32. Györffy, B.; Lanczky, A.; Eklund, A.C.; Denkert, C.; Budczies, J.; Li, Q.; Szallasi, Z. An online survival analysis tool to rapidly assess the effect of 22,277 genes on breast cancer prognosis using microarray data of 1809 patients. Breast Cancer Res. Treat. 2010, 123, 725-731. [CrossRef] [PubMed]

33. Alvarez-Fernandez, M.; Malumbres, M. Mechanisms of Sensitivity and Resistance to CDK4/6 Inhibition. Cancer Cell 2020, 37, 514-529. [CrossRef] [PubMed]

34. Gartside, M.G.; Chen, H.; Ibrahimi, O.A.; Byron, S.A.; Curtis, A.V.; Wellens, C.L.; Bengston, A.; Yudt, L.M.; Eliseenkova, A.V.; Ma, J.; et al. Loss-of-Function Fibroblast Growth Factor Receptor-2 Mutations in Melanoma. Mol. Cancer Res. 2009, 7, 41-54. [CrossRef] [PubMed]

35. Byron, S.A.; Gartside, M.; Powell, M.A.; Wellens, C.L.; Gao, F.; Mutch, D.G.; Goodfellow, P.J.; Pollock, P.M. FGFR2 point mutations in 466 endometrioid endometrial tumors: Relationship with MSI, KRAS, PIK3CA, CTNNB1 mutations and clinicopathological features. PLoS ONE 2012, 7, e30801. [CrossRef]

36. Pollock, P.M.; Gartside, M.G.; Dejeza, L.C.; Powell, M.A.; Mallon, M.A.; Davies, H.; Mohammadi, M.; Futreal, P.A.; Stratton, M.R.; Trent, J.M.; et al. Frequent activating FGFR2 mutations in endometrial carcinomas parallel germline mutations associated with craniosynostosis and skeletal dysplasia syndromes. Oncogene 2007, 26, 7158-7162. [CrossRef]

37. Grose, R.; Fantl, V.; Werner, S.; Chioni, A.-M.; Jarosz, M.; Rudling, R.; Cross, B.; Hart, I.R.; Dickson, C. The role of fibroblast growth factor receptor $2 \mathrm{~b}$ in skin homeostasis and cancer development. EMBO J. 2007, 26, 1268-1278. [CrossRef]

38. Amann, T.; Bataille, F.; Spruss, T.; Dettmer, K.; Wild, P.; Liedtke, C.; Mühlbauer, M.; Kiefer, P.; Oefner, P.J.; Trautwein, C.; et al. Reduced Expression of Fibroblast Growth Factor Receptor 2IIIb in Hepatocellular Carcinoma Induces a More Aggressive Growth. Am. J. Pathol. 2010, 176, 1433-1442. [CrossRef]

39. Katoh, Y.; Katoh, M. FGFR2-related pathogenesis and FGFR2-targeted therapeutics (Review). Int. J. Mol. Med. 2009, 23. [CrossRef]

40. DeSantis, C.E.; Ma, J.; Gaudet, M.M.; Newman, L.A.; Miller, K.D.; Goding Sauer, A.; Jemal, A.; Siegel, R.L. Breast cancer statistics, 2019. CA Cancer J. Clin. 2019, 69, 438-451. [CrossRef]

41. Hoon Tan, P.; Ellis, I.; Allison, K.; Brogi, E.; Fox, S.B.; Lakhani, S.; Lazar, A.J.; Morris, E.A.; Sahin, A.; Salgado, R.; et al. The 2019 WHO classification of tumours of the breast. Histopathology 2020. [CrossRef] [PubMed]

42. Allred, D.C.; Harvey, J.M.; Berardo, M.; Clark, G.M. Prognostic and predictive factors in breast cancer by immunohistochemical analysis. Mod. Pathol. 1998, 11, 155-168. [PubMed]

43. Wolff, A.C.; Hammond, M.E.H.; Allison, K.H.; Harvey, B.E.; Mangu, P.B.; Bartlett, J.M.S.; Bilous, M.; Ellis, I.O.; Fitzgibbons, P.; Hanna, W.; et al. Human Epidermal Growth Factor Receptor 2 Testing in Breast Cancer: American Society of Clinical Oncology/College of American Pathologists Clinical Practice Guideline Focused Update. Arch. Pathol. Lab. Med. 2018, 142, 1364-1382. [CrossRef]

44. Lal, P.; Salazar, P.A.; Hudis, C.A.; Ladanyi, M.; Chen, B. HER-2 testing in breast cancer using immunohistochemical analysis and fluorescence in situ hybridization: A single-institution experience of 2,279 cases and comparison of dual-color and single-color scoring. Am. J. Clin. Pathol. 2004, 121, 631-636. [CrossRef] [PubMed]

45. Borchert, S.; Wessolly, M.; Schmeller, J.; Mairinger, E.; Kollmeier, J.; Hager, T.; Mairinger, T.; Herold, T.; Christoph, D.C.; Walter, R.F.H.; et al. Gene expression profiling of homologous recombination repair pathway indicates susceptibility for olaparib treatment in malignant pleural mesothelioma in vitro. BMC Cancer 2019, 19, 108. [CrossRef] [PubMed]

46. Wu, C.; Mairinger, F.; Casanova, R.; Batavia, A.A.; Leblond, A.L.; Soltermann, A. Prognostic Immune Cell Profiling of Malignant Pleural Effusion Patients by Computerized Immunohistochemical and Transcriptional Analysis. Cancers 2019, 11, 1953. [CrossRef] [PubMed] 
47. Hudis, C.A.; Barlow, W.E.; Costantino, J.P.; Gray, R.J.; Pritchard, K.I.; Chapman, J.-A.W.; Sparano, J.A.; Hunsberger, S.; Enos, R.A.; Gelber, R.D.; et al. Proposal for Standardized Definitions for Efficacy End Points in Adjuvant Breast Cancer Trials: The STEEP System. J. Clin. Oncol. 2007, 25, 2127-2132. [CrossRef] [PubMed]

(C) 2020 by the authors. Licensee MDPI, Basel, Switzerland. This article is an open access article distributed under the terms and conditions of the Creative Commons Attribution (CC BY) license (http://creativecommons.org/licenses/by/4.0/). 